\title{
The Honey-lips e The Guarany: os romances de José de Alencar em língua inglesa no final do século XIX
}

\author{
The Honey-lips et The Guarani : les romans de José de Alencar \\ en langue anglaise à la fin du XIXe siècle
}

\section{Valéria Cristina Bezerra}

Universidade Estadual de Campinas - UNICAMP - Campinas - São Paulo - Brasil

\begin{abstract}
Resumo: Nas últimas décadas do século XIX, dois romances de José de Alencar tiveram tradução e circulação em países de língua inglesa. Iraçéma: the honey-lips, em versão de Isabel Burton, foi publicada em 1886 em Londres e contou com recepção crítica em jornais do Reino Unido. The Guarany, traduzido por James William Hawes, saiu em forma seriada no ano de 1893 no jornal Overland Monthly and Out West Magazine, de São Francisco, nos Estados Unidos, país em que Alencar também foi referido pela imprensa local. Este trabalho se propõe a analisar as formas de recepção dessas obras e do nome de José de Alencar no Reino Unido e nos Estados Unidos. Objetiva ainda verificar o papel dos tradutores, editores, críticos e da imprensa na configuração da maneira como esse escritor foi avaliado e dado a ler, buscando considerar, sempre que possível, a relação desses intermediadores com a cultura brasileira. A recepção crítica de Alencar nesses países revela a boa avaliação desse escritor e a tradução de seus romances parece ter respondido a um interesse do público estrangeiro de se ilustrar.
\end{abstract}

Palavras-chave: José de Alencar. Tradução. Recepção.

Abstract: Dans les dernières décennies du XIXe siècle, deux romans de José de Alencar ont été traduits et obtenu circulation dans des pays de langue anglaise. Iraçéma : the honey-lips, version de Isabel Burton, est apparue en 1886 à Londres, en suscitant la réception critique dans des journaux du Royaume-Uni. The Guarany, traduit par James William Hawes, est sorti de façon découpée en 1893 dans le journal Overland Monthly and Out West Magazine, de San Francisco, aux États-Unis, pays où Alencar a aussi été mentionné par la presse locale. Ce travail se propose d'analyser la réception de ces ouvrages et de José de Alencar dans le Royaume-Uni et les ÉtatsUnis. II a également pour but de vérifier le rôle des traducteurs, éditeurs, critiques et de la presse dans la configuration de l'évaluation de cet écrivain et de ses œuvres dans ces pays, en considérant, toujours que possible, le rapport de ces passeurs avec la culture brésilienne. La réception critique de Alencar dans ces pays révèle sa bonne évaluation aussi bien que la traduction de ses romans semble avoir répondu à l'intérêt du public étranger à s'illustrer.

Keywords: José de Alencar. Traduction. Réception. 


\section{Introdução}

Muito se conhece hoje sobre o papel de José de Alencar no chamado Romantismo brasileiro e de sua atividade para a criação de uma literatura nacional, esforço que lhe rendeu uma obra volumosa e sua permanência nos quadros escolares. Canonizado pelas histórias literárias, as quais repetem entre si informações que ficaram no senso comum sobre o escritor, Alencar teve uma dimensão de sua produção esquecida pela historiografia, a da difusão internacional de suas obras ainda no século XIX. Traduzido para o italiano, alemão, inglês e francês, Alencar estendeu o alcance da literatura brasileira e galgou patamares para o reconhecimento da produção literária do Brasil no exterior, fator ambicionado pelos homens de letras brasileiros que viam na repercussão e avaliação internacional uma maneira de concretizar a legitimação da literatura da jovem nação. Uma nota saída na imprensa francesa mostra a repercussão das traduções de $O$ Guarani por ocasião da entrada do romance naquele país, sob o título Le fils du soleil:

Très populaire dans tous les pays de langue portugaise, le Fils du Soleil - ou le Guarani a retrouvé le même succès dans toutes les traductions qui en ont été faites, en italien, en allemand et en anglais. II était vraiment étonnant que le roman d'Alencar n'eût pas encore son traducteur français.

[Muito popular em todos os países de língua portuguesa, o Fils du Soleil - ou o Guarani encontrou o mesmo sucesso em todas as traduções que foram feitas, em italiano, em alemão e em inglês. É realmente surpreendente que o romance de Alencar não tenha tido ainda um tradutor francês] (Le Temps, n. 15134, 20 nov. 1902, p. 3, tradução nossa).

Considerando a inserção das obras de Alencar nos mais diversos idiomas e países, examinaremos, neste trabalho, as formas de circulação e recepção de José de Alencar e de duas de suas obras em língua inglesa, Iracema (Iraçéma: the honey-lips) e $O$ Guarani (The Guarany), atentando para o papel dos intermediadores nessa difusão, como tradutores e editores, cujas formas de atuação, além de promoverem a cultura brasileira, modelaram a incursão e avaliação dos romances de Alencar nos países de língua inglesa.

\section{Tradutores, editores, críticos e imprensa: a difusão das obras de Alencar no Reino Unido e Estados Unidos ${ }^{1}$}

Iracema, the honey-lips foi publicada em 1886, em tradução assinada por Isabel Burton. A tradutora viveu no Brasil entre 1865 e 1868, devido às funções consulares do marido, Richard Francis Burton, que atuava na cidade de Santos. Richard e Isabel Burton cultivaram uma vida aventureira e desbravadora, experiências que the resultaram em vários livros de viagem ou traduções de obras dos países em que estiveram. Isabel Burton secundou o marido em suas atividades e deu-lhe suporte na concepção, edição e publicação de seus livros, sem contar as boas relações sociais que tecia em nome da promoção da carreira de Richard Burton. A tradutora dominava o francês, língua com a qual se comunicava com a família Imperial brasileira - a qual recebia visitas do casal -, e aprendeu a língua portuguesa no Brasil, onde tomou aulas desse idioma (LOVELL, 1998; BURTON; WILKINS, 1897). Nas suas cartas destinadas à mãe, transcritas em sua autobiografia, Isabel Burton relatou momentos de conversação e de estudo do português. Ainda de acordo com Isabel Burton, em um trecho de correspondência a Lord Houghton, Richard Burton falava perfeitamente o português. Tal domínio o levou a realizar leituras sobre o Brasil e a desenvolver trabalhos voltados para a cultura desse país, como revelou em carta ao amigo Albert Tootal em fevereiro de 1868:

I have finished my translation of Uruguay and am copying it out for print. My daily work begins at 6 a.m. and ends at 10 p.m.; there is an immensity of reading to be done before one can write about the Brazil.

[Eu concluí a minha tradução de Uruguay e estou transcrevendo-a para a impressão. Meu dia de trabalho começa às 6 da manhã e termina às 10 da noite; há uma imensidão de

\footnotetext{
${ }^{1}$ Este trabalho é resultado de pesquisa de campo realizada entre abril e maio de 2015 na British Library, em Londres, como parte das atividades do Programa Bolsa Estágio de Pesquisa no Exterior - BEPE/Fapesp.
} 
leituras a fazer antes que se possa escrever sobre o Brasil] (LOVELL, 1998, p. 471, tradução nossa).

A tradução do poema de Basílio da Gama só foi publicada no século XX, em 1982, embora Richard Burton tivesse grande interesse em dar publicidade a obras brasileiras. Em artigo para a revista The Atenaeum de 24 de fevereiro de 1872, espécie de carta aberta ao presidente da Royal Geographical Society, questionou a preponderância do idioma francês e de suas traduções pelo mundo, alegando a necessidade de a Inglaterra conhecer outras culturas. Para isso propôs a criação de um "General Translation Fond", cuja finalidade seria incrementar a oferta de livros estrangeiros para além da cultura francesa, concentrando-se nos de origem brasileira. Tendo uma de suas traduções recusadas por um editor, que argumentou que traduções "não se pagam", Burton defendeu a importância desse exercício para o âmbito inglês:

But you will expect me to establish the fact that French literature has that one great advantage over English, and that translations, whether they pay or not, are, at any rate, printed and published, circulated and read by our neighbours [...]. As the field is wide, and your space is narrow, we had better confine ourselves to a single corner of the ground, the literature of the Brazil. Others may speak of Scandinavian, Dutch, Walloon, Flemish, Basque, Bernais, Spanish, Portuguese, Russian, Greek, and many others, too many to enumerate.

A digression. I should much like to know how many of your numerous and learned readers are familiar with the details of Brazilian literature.

[Mas você há de concordar comigo quanto ao fato de que a literatura francesa tem essa grande vantagem sobre a inglesa, e que as suas traduções, quer elas paguem ou não, são, de qualquer maneira, impressas e publicadas, difundidas e lidas por nossos vizinhos [...]. Como o campo é largo, e o seu espaço estreito, poderíamos nos limitar a um único canto do terreno, a literatura do Brasil. Outros podem falar da literatura escandinava, holandesa, valona, flamenga, basca, bearnesa, hispânica, portuguesa, russa, grega, e muitas outras, impossíveis de serem enumeradas aqui.

Uma digressão. Eu gostaria muito de saber quantos entre os seus numerosos e cultos leitores são familiares aos aspectos da literatura brasileira (The Athenaeum, n. 2313, 24 Feb.1872, p. 242, tradução nossa).
No artigo, Burton destacou que franceses e alemães tinham acesso a informações sobre a literatura do Brasil a partir dos trabalhos de Ferdinand Denis e Ferdinand Wolf, enquanto para os ingleses as letras brasileiras representavam um campo desconhecido. Ressaltou ainda a existência das traduções francesas de Caramuru e Marília de Dirceu. Esses fatores, segundo Burton, reforçavam o seu argumento sobre a importância de os homens de letras ingleses se deterem nas traduções de obras brasileiras. Para tanto, Burton listou uma série de títulos que, ao seu ver, precisava ser vertida para o inglês:

I copy from my notebook an abstract of what might be made a long list calling for translation [Transcrevo de meu caderno de notas um resumo do que deve formar uma longa lista de obras que esperam por tradução]:

1. The detached papers of Dr. de Lacerda.

2. Cartas Chilenas, popularly attributed to Gonzaga, like the 'Lyras', called 'Marilia de Dirceu'. (Rio, Garnier, 1862.)

3. Confederação dos Tamoyos of Magalhaens.

4. Collecção Completa das Maximas do Marquez de Marica. [...]

5. The School History of the Brazil, by General José Ignacio de Utica e Lima.

6. Historia dos Indos (sic) Cavalleiros da Nação Guaycurú, by Francisco Alves de Prado.

7. Vasconcellos, Chronica da Compania (sic) de Jyces (sic) [Jesus] do Estado do Brasil.

8. Orbe Serafico, by Antonio de Santa Maria de Jaboatão.

9. Cartas Selectas, by the Padre Antonio Vieira.

10. Poetry of Antonio Gonsalez (sic) Teixeira e Souza.

11. Poetry of Joaquim Roberto (sic) de Souza Silva especially.

12. Romances, por Joaquim Manoel de Macero (sic).

13. A Assumpção, por Frei Francisco de S. Carlos. (Rio, Garnier, 1862.)

14. Selections from the Revista Trimestral do Instituto Historico Geografico e Ethnographico of Rio de Janeiro. (Thirty volumes.)

15. The Geographical Works of Mendes de Almeida.

16. The very valuable statistical work upon the Amazons, by the Deputy Tavares Bastos.

17. Obras de João Francisco Lisboa. (4 vols. S. Luiz do Maranhão, 1864.)

18. Discursos Parlamentares of Dom Gabriel José Rodrigues dos Santos. (Rio, 1863.) 
19. Calabar, Historia Brasileira (Rio, 1863.) (The Athenaeum, n. 2313, 24 Feb.1872, p. 242, tradução nossa, ortografia conforme original).

Principalmente a história e a literatura estavam no cerne dos interesses de Burton, que entendia ser possível oferecer aos leitores ingleses uma amostra significativa para conhecimento do país a partir desses títulos. Livros de poesia, de romance e de história, do passado ou coetâneos, se misturavam, adquirindo status semelhante entre si. Chama a atenção a presença da obra do escritor português Mendes Leal, Calabar, romance histórico ambientado no Brasil, o qual, certamente por essa razão, foi incorporado por Burton entre aquelas representativas da nação. No artigo, Richard Burton mencionou ainda as traduções que já tinha realizado: O Uruguai, de Basílio da Gama; Manoel de Moraes, de Pereira da Silva, e Iracema, de Alencar (apesar de a tradução desse romance aparecer assinada por sua esposa, Isabel Burton, o trabalho colaborativo entre os dois impõe fronteiras muito tênues de autoria). Sobre Alencar, acrescentou ainda que

[He] has produced historical novels which rank amongst the highest of their school, yet ' $O$ Guarani' is as little known in England as the admirable prose fictions of Prof. Herculano, of Lisbon.

[Ele tem produzido romances históricos que se situam entre os maiores de sua escola; apesar de $O$ Guarani ser tão pouco conhecido na Inglaterra quanto as admiráveis prosas ficcionais do Prof. Herculano, de Lisboa] (The Athenaeum, n. 2313, 24 Feb.1872, p. 242, tradução nossa).

Nem o Guarani tampouco os romances de Herculano haviam sido publicados em inglês até esse ano de 1872. Possivelmente, Burton devia estar levando em conta para esse conhecimento, ainda que restrito, dos dois escritores, o círculo de letrados que, como ele, se empenhava no conhecimento de outras culturas e idiomas, dentre os quais, o português:

Many must want time to master its [Brazil's] language, which is certainly the most difficult of those neo-Latin tongues [...]. More have been deterred from studying Brazilian by the trouble and difficulty of importing books [...]. [Muitos devem querer ter tempo para dominar a língua do Brasil, a qual é certamente a mais difícil das línguas neolatinas [...]. Muitos mais têm sido desencorajados do estudo do "brasileiro" devido aos transtornos e dificuldades da importação de livros] (The Athenaeum, n. 2313, 24 Feb. 1872, p. 242, tradução nossa).

O fato ganha reforço quando observamos uma relevante presença de obras literárias brasileiras em idioma original adquiridas na época pela biblioteca do British Museum, que tinha o cuidado de carimbar os livros que dispunha para o público, informando o ano de sua aquisição - fundos que compõem atualmente a British Library. Todas as obras literárias brasileiras do acervo contêm um carimbo na cor vermelha, com indicação de data, ao final do exemplar. A cor vermelha designa que a obra foi comprada pela biblioteca (HARRIS, 2009). Constam no acervo as primeiras edições de Iracema (1865), de O Gaúcho (1870) e de Sonhos d'Ouro (1872); O Guarani em tradução alemã de 1876, assim como a versão germânica de Ubirajara de 1886; a edição de Senhora de 1888, para citar todas as obras de Alencar presentes no arquivo, além de exemplares coetâneos de vários romances e peças de teatro de Joaquim Manoel de Macedo, dos livros de poesia Crisálidas e Falenas, de Machado de Assis, de seu romance Ressurreição e dos Contos Fluminenses. Todos esses livros foram adquiridos alguns anos após a sua edição ou ainda no mesmo ano em que foram publicados.

Causa surpresa a existência de obras literárias brasileiras em versão original no acervo da mais importante biblioteca do Reino Unido, existente desde meados do século XVIII e pertencente a um prestigiado centro como o British Museum. Quem teria decidido pela aquisição dessas obras e escolha dos títulos? Para que público? Com que finalidade? $\mathrm{O}$ fato se mostra bastante instigante, merecendo ser devidamente esclarecido. Decerto, havia um público que eventualmente poderia se interessar por tais títulos.

E possivelmente, em meio a esse mesmo tipo de público, Burton contava com o interesse em traduzir ou subsidiar a tradução de obras brasileiras. Trechos do seu artigo para a revista The Athenaeum foram vertidos para o português e reproduzidos um 
mês depois em O Novo Mundo, revista editada em Nova York por José Carlos Rodrigues, com quem o casal também estabeleceu relações, como revela carta de Isabel Burton destinada ao editor em 21 de maio de 1872 - conservada atualmente na Fundação Biblioteca Nacional do Rio de Janeiro. A carta tinha como assunto as traduções do romance Melo de Moraes, de Pereira da Silva; de Iracema, de Alencar, além de um terceiro manuscrito de obra e autoria não identificadas. Alegando ter sido a única tradutora de Iracema, Isabel Burton escreveu ao editor do Novo Mundo que iria lhe remeter os originais da tradução, pedindo-lhe que os comparasse com o romance original a fim verificar a qualidade de seu trabalho. Pelo que se depreende do documento, Isabel Burton confiou a José Carlos Rodrigues a edição das obras, fato comprovado por The Publishers' and Stationers' Weekly Trade Circular, de Nova York, ainda no mesmo ano de 1872:

The editor of "O Novo Mundo", New York, announces that he will publish in the course of the following year a couple of translations by Captain Richard F. Burton from the works of Brazilian authors, namely: "Manuel de Moraes", by Sr. Pereira da Silva; and "Iracema", by Sr. J. de Alencar.

[O editor de O Novo Mundo, Nova lorque, anuncia que irá publicar no decurso do próximo ano duas traduções do Capitão Richard F. Burton, originadas de obras de autores brasileiros, intituladas: Manuel de Moraes, do Sr. Pereira da Silva; e Iracema, do Sr. J. de Alencar] (The Publishers' and Stationers' Weekly Trade Circular. New York, n. 20, 14 Nov. 1872, p. 513, tradução nossa).

Não se conhecem as razões de a referida edição nunca ter saído a lume. Em sua autobiografia, Isabel Burton não descreveu nenhum momento seu de trabalho literário no Brasil, apenas os do marido, sem chegar a mencionar a tradução de Iracema ou o nome de Alencar entre as vivências relatadas no país (BURTON; WILKINS, 1897). Apenas na biografia que escreveu sobre Richard Burton é que a autora fez menção à tradução do romance, informando que a publicação foi custeada por eles mesmos: "We brought out our little translation from the Brazilian of 'Iracema' and 'Manoel de Moraes, the Convert' at our own expense [Publicamos nossa pequena tradução de Iracema e Manoel de Moraes, o Convertido, ambos originais do 'brasileiro', às nossas custas]"
(BURTON, 1893, p. 294, tradução nossa). Iracema parece ter sido vertida para o inglês durante a estadia do casal no Brasil na década de 1860, uma vez que o prefácio da edição, assinado por Isabel Burton, traz, ao final, a indicação da cidade de Santos. Nesse mesmo texto, a autora informou que Alencar lhe deu pessoalmente instruções a respeito do Tupi (BURTON, 1886), o que evidencia que o escritor e os tradutores mantiveram contato. A folha de rosto destaca que a tradução obteve a devida autorização do autor.

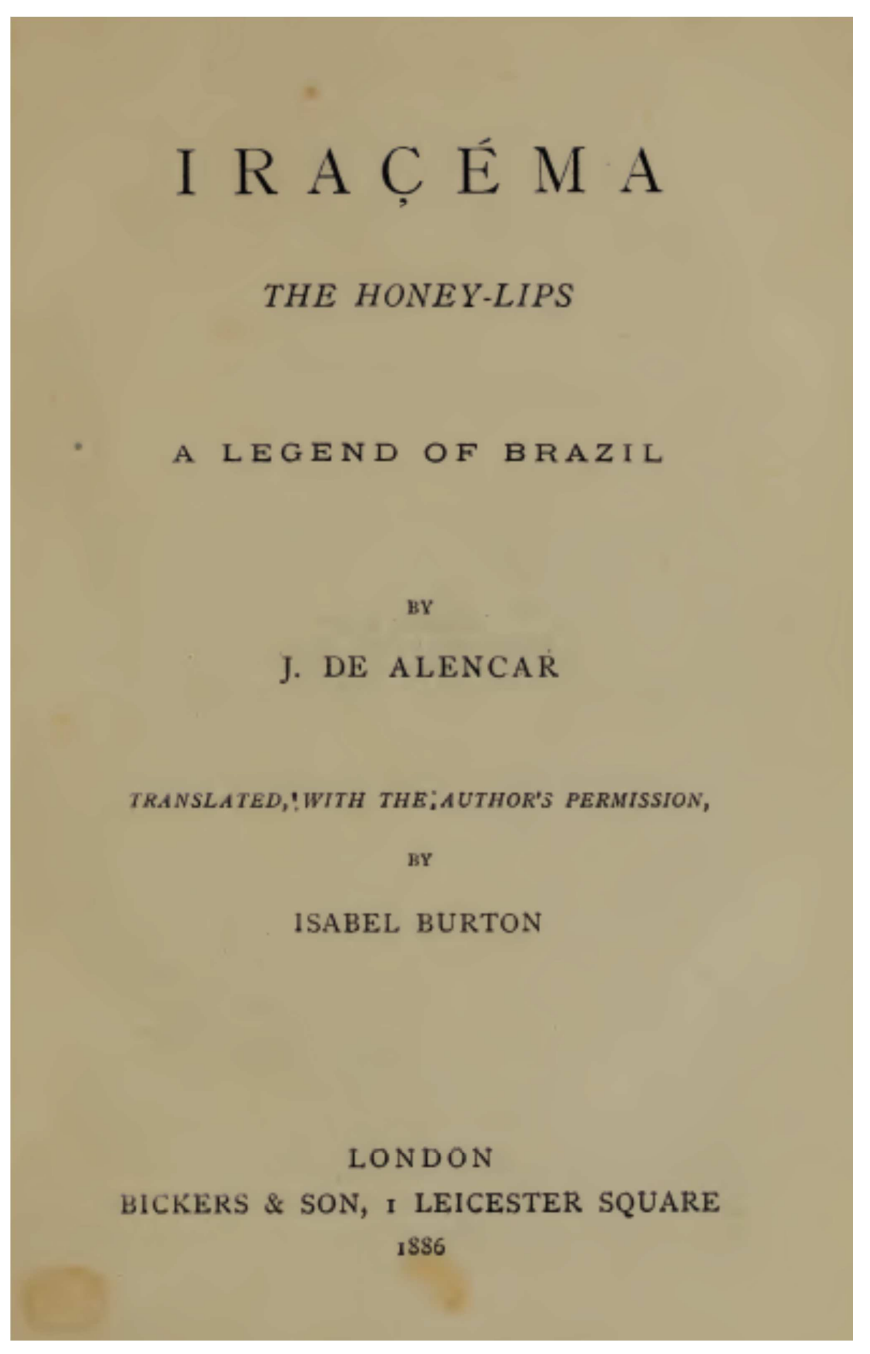

THE HONEY-LIPS

Ao público inglês, Isabel Burton apresentou Alencar como o primeiro representante da prosa de ficção brasileira:

I cannot allow my readers to remain ignorant of the name of Senhor J. de Alencar, the author of this and several other works; for he deserves to be as well known in England as in Brazil, and it must be the result of the usual modesty of a really clever man that he is not so. He is their first prose and romance writer. His style, written in the best Portuguese of the 
present day - one to be learnt and copied - is in thorough good taste and feeling. It contains poetic and delicate touches, and beauty in similes, yet it is real and true to life.

[Não posso permitir aos meus leitores que permaneçam ignorando o nome do Senhor J. de Alencar, o autor dessa e de outras várias obras; pois ele merece ser tão conhecido na Inglaterra como no Brasil, celebridade que deve ser resultado da usual modéstia de um homem verdadeiramente inteligente que não se arroga dessa imagem. Ele é o primeiro romancista do Brasil. Seu estilo, escrito no melhor português da atualidade - o único a ser aprendido e imitado -, é perpassado de bom gosto e sentimento e contém toques delicados e poéticos, belo em símiles, sendo ainda real e verdadeiro com a vida] (BURTON, 1886, p. iii, tradução nossa).

Ao que se vê, Alencar foi apresentado como escritor que devia ser conhecido do público estrangeiro devido à sua representatividade para as letras brasileiras e pela qualidade de escrita de seu trabalho literário, aspecto reforçado nas apreciações da tradutora quanto à sua dificuldade de verter o estilo do escritor para o inglês:

I have endeavoured to be as literal as possible, but I cannot pretend to do him [Alencar] justice, for our harsh Northern tongue only tells coarsely a tale full of grace and music in Portuguese language.

[Eu me empenhei em ser o mais literal possível, mas não pretendo com isso ter feito justiça ao escritor, pois a nossa áspera língua transmite apenas grosseiramente uma história que se apresenta cheia de graça e musicalidade em língua portuguesa (BURTON, 1886, p. iii, tradução nossa).

As experiências de Isabel Burton no Brasil, sobretudo a expedição de dois meses que fez pela província de Minas Gerais junto ao marido, the propiciaram um conhecimento da paisagem que certamente contribuiu para o emprego de imagens e vocábulos na composição da tradução, como se identifica em sua fascinação pela natureza do interior do Brasil em carta à mãe de junho de 1868 (BURTON; WILKINS, 1897, p. 348-349). Na mesma carta, às vésperas de retornar à Inglaterra, Isabel Burton confessou o interesse em publicar alguns dos escritos elaborados pelo casal durante sua estadia no Brasil, mas apenas em 1886 é que a versão em inglês de Iracema foi dada à estampa, juntamente com Melo de Moraes, de Pereira da Silva. A edição saiu pela Bickers and Son, editores sediados na Leicester Square, em Londres.

O Publishers' Circular, de 1890, asseverou que os editores homônimos (pai e filho tinham o mesmo nome, Henry Bickers) desenvolveram "one of the most renowned businesses in London [um dos mais renomados negócios de Londres]" (Publishers' Circular, 1 May 1890, p. 498, tradução nossa). A loja em que se instalava a livraria, nos idos dos anos de 1890 , era "rather representative of a gentleman's library than a show room [antes representativa de uma biblioteca de um gentleman do que uma livraria]" (Publishers' Circular, 1 May 1890, p. 498, tradução nossa). No tempo em que o romance Iracema foi publicado, os fundadores da empresa que assina a edição não estavam mais vivos e o negócio era administrado por seu antigo funcionário, Mr. John Harwood. Perguntado sobre a característica principal da Bickers and Son, Harwood declarou: "We have been noted here as high-class booksellers, principally standard editions bound in first-class bindings [Destacamo-nos como vendedores de livros de alta classe, conhecidos principalmente pelas edições com encadernações de luxo]". Ao final do artigo, o jornalista elogiou o trabalho de Harwood, ao seu ver "competent to hold his own with any contemporary bookseller, in the selection of such works as go to form an English gentleman's library [Competente em gerir o seu negócio ao lado de qualquer outro livreiro contemporâneo, através da seleção de obras que poderiam compor uma biblioteca de um 'gentleman' inglês]" (Publishers' Circular, 1 May 1890, p. 498, tradução nossa). Vê-se pela descrição que a editora parecia voltada para a publicação de livros destinados a um público bastante selecionado: o dos "gentlemen" ingleses.

Consultando no catálogo da British Library, no Google Books e no World Catalogue os livros publicados pela Bickers and Son, identificamos uma extensa variedade de títulos concernentes a livros de História, de viagem, de poesia, de artes, técnicos, científicos, educacionais, religiosos, biografias. Eram ainda especializados na publicação das obras de Shakespeare ou sobre ele. Foram localizados nesses 
catálogos alguns poucos romances editados pela Bickers and Son. Não descobrimos os laços estabelecidos entre o casal Burton e John Harwood e nem a razão exata da escolha da editora pelos tradutores para a publicação dos romances de Alencar e Pereira da Silva, mas, a partir do perfil da Bickers and Son, podemos pressupor que a edição conjunta de Iracema e Melo de Moraes não tenha sido dada a público com o fim de oferecer-lhe romances populares de aventura, tal qual ocorreu na França com a publicação de $O$ Guarani na coleção popular "Bibliothèque des grandes aventures" (HEINEBERG, 2015). As palavras de Isabel Burton, na passagem citada acima, corroboram essa interpretação no que diz respeito ao autor de Iracema: "I cannot allow my readers to remain ignorant of the name of Senhor J. de Alencar, [...] first prose and romance writer" (BURTON, 1886, p. iii).

Por essa época, a Inglaterra contava com um relevante número de leitores, resultante de várias iniciativas educacionais colocadas em prática ao longo do século, as quais culminariam por fim na criação da lei de Mundella, em 1880, que determinava o ensino elementar obrigatório e gratuito. A atividade das circulating libraries, o estabelecimento de bibliotecas públicas e a supressão de taxas sobre o direito de impressão, em 1855, e sobre o papel, em 1861, favoreceram o acesso aos impressos. No entanto, apesar de o gênero romance contar com uma popularização a partir de sua veiculação em folhetim ou em fascículos, a sua publicação em livro continuava representando um obstáculo para a sua aquisição pelo grande público (CACHIN, 2010). Donde podemos concluir que a tradução de Iracema na Inglaterra teve destinação a um público específico, interessado no conhecimento de uma obra representativa da literatura brasileira, aspecto reforçado pela recepção crítica do romance. O jornalista anônimo de The Freeman's Journal, de Dublin, divulgou suas impressões quanto às palavras de Isabel Burton expressas no prefácio e suas expectativas em relação ao romance:

Mrs. Burton assures us that $\mathrm{J}$. de Alencar, the writer of this tale, is a gifted and distinguished
Brazilian author, who has made his mark on the literature of his country, and that she is happy to be the medium of introducing him to the English public, with whom his works are sure to become favourites. We are not acquainted with the ways and manners of her in Brazil, and, are, therefore, unable to speak with any authority as to the fidelity or otherwise with which the writer of the legend has depicted them. But we can safely say that Mr. (sic) Burton's translation seems to be a very good one, and is very readable, and that the little book is excellently brought out by Bickers and Son, of Leicester Square, London. [A senhora Burton nos assegura que J. de Alencar, o autor dessa narrativa, é um talentoso e distinto escritor brasileiro, que deixou a sua marca na literatura de seu país, e que ela está feliz por ser a mediadora de sua apresentação ao público inglês, junto a quem certamente as obras do escritor se tornarão favoritas. Não somos familiares aos modos e costumes da tradutora no Brasil e, consequentemente, somos incapazes de julgar com autoridade quanto à fidelidade da tradução ou ainda da representação da lenda feita pelo escritor. Mas podemos seguramente dizer que a tradução parece ser muito bem realizada, de leitura fácil, e que este pequeno livro foi primorosamente publicado pela Bickers and Son, da Leicester Square, Londres] (The Freeman's Journal, 22 Jan. 1886, p. 2, tradução nossa).

Já o autor da seção "Literature" do jornal The Glasgow Herald tinha opinião distinta quanto à qualidade da tradução e sua legibilidade. Ele qualificou o romance como uma "curiosidade literária" e corroborou as palavras de Isabel Burton ao apresentar Alencar como "the first reputation as a prose and romance writer in Brazil [o mais renomado romancista no Brasil]", cujo estilo seria caracterizado pela elegância do uso do idioma português. No entanto, o jornalista fez críticas ao trabalho de Isabel Burton por julgar que esse tipo de obra seria intraduzível, dada a distinção da língua portuguesa com a inglesa, e que chegaria a ser insana a tentativa de transposição literal do texto. Após a transcrição da abertura do romance, julgou que

Such flowery language is not palatable to our matter-of-fact northern taste, and when the innumerable tropical allusions require to be explained by an elaborate system of footnotes which fill a third of the pages, it is clear that Senhor de Alencar is not likely to become a popular novelist in this country.

[Tal linguagem floreada não é palatável para o nosso gosto pragmático, e quando as inumeráveis alusões tropicais exigem explicações por meio de um elaborado 
sistema de notas de rodapé que preenche um terço das páginas, fica claro que o Senhor Alencar provavelmente não se tornará um romancista popular neste país] (The Glasgow Herald, 18 Feb.1886, p. 3, tradução nossa).

Ao que parece, a forma como Alencar foi oferecido no Reino Unido o distanciava de qualquer acolhida popular. A recepção crítica de Iracema nesse país indicava a obra como representativa de uma literatura nacional, proveniente da pena de seu principal literato. Por essa época, a crítica nos Estados Unidos também oferecia apreciações a respeito de Alencar, em geral elogiosas. O escritor foi apresentado como detentor de qualidade artística em nota anônima veiculada na Appletons' Annual Cyclopedia:

He [Alencar] [...] wrote various dramas, poems, and romances, some of which, such as his poem of "Iracema", and his romances of "The Guarany" and "Urabijara" (sic), all founded on Indian legends of Brazil, rank among the finest literary productions of the country.

[Escreveu vários dramas, poemas e romances, alguns dos quais, como o seu poema Iracema, e os seus romances $O$ Guarani e Ubirajara, todos baseados nas lendas indígenas do Brasil, estão entre as melhores produções do país]" (Appletons' Annual Cyclopedia, 1889, p. 591, tradução nossa).

A Johnson's Universal Cyclopedia (1898) incluiu um verbete sobre o escritor, de autoria de H.H. Smith, que informava serem os romances de Alencar tematizados pela "vida indígena e colonial", pelos quais o escritor seria conhecido como o Cooper brasileiro. Citou alguns desses romances, mas não esqueceu de mencionar aqueles em que o autor contemplaria "a vida social do Rio de Janeiro" ( $p$. 108). Com pequena variação em relação a esse texto, - suplemento da Encyclopaedia Britannica, publicação estadunidense apesar do título, também disponibilizou um verbete sobre o escritor nesse mesmo ano de 1898 (KELLOGG).

Além das enciclopédias, outras fontes em língua inglesa forneceram informações sobre Alencar nesse período. Em 1887, em livro intitulado Brazil, its conditions and its prospects, Christopher Columbus Andrews, que atuou como Cônsul Geral dos Estados
Unidos no Brasil, dedicou um capítulo à literatura brasileira, no qual destacou o papel de Alencar, Macedo e Bernardo Guimarães para as letras no país. Sobre Alencar, informou ser um escritor prolífico, com em média 30 obras de sua autoria, dentre as quais Iracema e O Guarani eram vistos como os melhores. Após apresentar um resumo biográfico de Alencar, ofereceu a tradução do "Argumento Histórico" de Iracema, o resumo de seu enredo e a tradução de uma passagem do romance. Descreveu ainda brevemente $O$ Guarani e colocou Alencar ao lado de Gonçalves Dias, os quais cultivariam, cada um em seu gênero de predileção, uma "espécie de estilo nativo". Ambos, embora muito apreciados, não teriam formado seguidores na literatura do país, segundo o autor (ANDREWS, 1887, p. 217-221). Já a revista nova-iorquina The Critic, em artigo sobre a literatura brasileira publicado em 1890, situou lado a lado Macedo e Alencar, "the two most distinguished names [os dois mais distintos nomes]" do âmbito literário brasileiro (The Critic, 10 May 1890, p. 235). O autor do artigo, Rollo Ogden, enfatizou ainda o sucesso editorial de $O$ Guarani no Brasil. Esse mesmo artigo foi veiculado no Daily Alta California em 1ํ de junho de 1890.

Esse interesse por Alencar certamente suscitou a tradução em língua inglesa de $O$ Guarani, veiculada em 1893 na Overland Monthly and Out West Magazine. É provável que a publicação, original de São Francisco, tenha alcançado a Europa, sendo conhecida na Inglaterra ou em outros países desse continente onde houvesse leitores nesse idioma. A revista, fundada em 1868, teve suas atividades encerradas em 1875, voltando a ser editada em 1883 de maneira ininterrupta até 1900. O seu criador, Anton Roman, um comerciante de livros de São Francisco, tinha como fim levar a público um periódico mensal "[that] should be, in some worthy sense, an exponent of the literature of the Pacific coast [que deve ser, num estimável sentido, um incentivador da literatura da costa do Pacífico]" (Overland Monthly, Jan. 1883, p. 1, tradução nossa). Para tanto, tinha em vista a formação de um público junto aos homens educados - que apreciavam a 
erudição e a cultura mesmo estando espalhados nas fazendas e nos campos -, profissionais especializados, além de mulheres com interesses intelectuais. A revista oferecia artigos de natureza variada, com algumas seções fixas, dentre elas a intitulada "Current Literature"; além de poesias e textos de prosa de ficção, inclusive romances. O tradutor de O Guarani, James William Hawes, foi advogado e militante em associações e organizações republicanas. Colaborava para diversas enciclopédias dos Estados Unidos, dentre as quais as da editora Appleton, onde foram difundidos verbetes sobre Alencar. Hawes traduziu ainda para a Overland Montly uma narrativa intitulada "A carta do Brasil", do português José Augusto Vieira, e publicou um artigo sobre a então mais recente Constituição Brasileira. Não se sabe como Hawes conheceu a língua portuguesa e por que meios mantinha contato com a cultura e política do Brasil.

Ao que se percebe, a literatura contemplada pela revista não se deteve à costa do Pacífico, chegando mesmo a este lado do Atlântico. Talvez alguma identificação partilhada por ambos os países quanto à história e à paisagem do Novo Mundo, com seus habitantes naturais indígenas e as lutas da colonização, tenha motivado o interesse pela tradução e publicação de $O$ Guarani, como sugere uma nota sobre o romance de junho de 1893:

It is full of the noble red man, of gallants and villains, of fair damsels, and of fierce beasts, curiously suggestive of our own early fiction, Cooper's in special.

[Essa obra está repleta de nobres homens vermelhos, de heróis e vilões, de belas donzelas e animais ferozes, - curiosamente sugestiva dos primórdios da nossa própria ficção, a de Cooper em especial] (Overland Monthly, n. 126, June 1893, p. 8, tradução nossa).

Em texto de apresentação desse romance, de janeiro de 1893, Hawes destacou a curiosidade dos leitores dos Estados Unidos por narrativas que oferecessem imagens do Brasil, tais as escritas por autores como Mayne Reid e Alice Wellington Rollins; no entanto, alegou que eram bem poucas as traduções de obras produzidas pelos brasileiros. Informou ainda ao público sobre o sucesso de $O$
Guarani no seu país de origem, onde era provavelmente "the most popular of Brazilian stories [a mais popular das histórias brasileiras]" (Overland Monthly, Jan. 1893, p. 81, tradução nossa). Mas, no índice da revista, não é o nome de Alencar que figura ao lado do título, e sim o de seu tradutor. De acordo com Hawes, ao sucesso da obra e seu autor no Brasil não corresponderia a sua difusão entre os falantes do inglês, cuja recepção, segundo esclarecia, se restringiria aos verbetes contidos nas edições da Appleton Cyclopedia. Hawes ofereceu breves informações biográficas sobre Alencar e concluiu mencionando algumas de suas obras:

His principal works are a poem, "Iracema", and two romances, "Urabijara" (sic) and "The Guarani". The latter has been translated into German, and an opera founded on it has been played in New York.

[Suas principais obras são um poema, Iracema, e dois romances, Ubirajara e $O$ Guarani. Este último foi traduzido em alemão, e uma ópera baseada nesse romance foi encenada em Nova York] (Overland Monthly, Jan. 1893, p. 81, tradução nossa).

O romance apareceu integralmente publicado na Overland Monthly and Out West Magazine entre janeiro e dezembro de 1893, com capítulos saídos em todos os números da revista durante sua veiculação. Não localizamos nenhuma edição em livro dessa tradução no período pesquisado ou mesmo durante o século XX. A versão ganhou uma edição digital recente estabelecida por Daniel Serravalle e Emilene Lubianco de Sá, disponível na biblioteca digital de literatura brasileira da Universidade Federal de Santa Catarina.

\section{Conclusão}

Durante sua atividade, Alencar esteve consciente das iniciativas para a tradução e difusão de suas obras no exterior. Ao comentar o insucesso da peça $O$ Jesuíta na corte fluminense, em 1875, declarou: "Desde muito descobri que o meu público é mais brasileiro e até mais estrangeiro do que carioca" (ALENCAR, O Globo, 26 set. 1875); na série de artigos "Às Quintas", em que respondia a Nabuco, informou: "Iracema foi traduzida em inglês pelo 
Capitão Burton, que aprecia e conhece melhor a natureza do Brasil, do que o folhetinista" (1965, p. 205). O escritor sabia da importância de ser conhecido nos grandes centros para a legitimação e permanência de seus escritos, mas levariam alguns anos após a sua morte para que as traduções de seus romances chegassem aos países de língua inglesa. Contudo, vimos que a incursão de suas obras e do nome do escritor no Reino Unido e nos Estados Unidos contou com intermediadores que favoreceram a sua boa recepção.

Isabel Burton e Richard Burton desfrutavam de boas relações e detinham reconhecida erudição, resultante de seus esforços nas letras e na divulgação dos méritos culturais dos países por que passavam. No caso do Brasil, dentre os autores que chamaram a atenção do casal, esteve José de Alencar, cujo romance Iracema foi traduzido e publicado em livro num país em que esse era um produto para poucos, tendo sido impresso por uma prestigiosa editora da época. Logo a novidade chamou a atenção de críticos, que não deixaram de elogiar as qualidades da obra. Nos Estados Unidos, o nome de Alencar passava a fazer parte das enciclopédias editadas nesse país, suporte que carrega em si o poder de vulgarizar o conhecimento, dando visibilidade às personalidades referenciadas. $A$ tradução do romance $O$ Guarani nos Estados Unidos fez uso de um recurso reconhecidamente popular, o da difusão seriada, em capítulos, próprio do romancefolhetim, por exemplo. The Overland Monthly empregava recursos editoriais de massa, mas buscou conquistar uma imagem positiva argumentando que oferecia a leitores com interesses refinados literatura de qualidade.

A boa avaliação atribuída a Alencar no Reino Unido e nos Estados Unidos esteve coadunada com a representatividade que o escritor assumia nesse final de século no Brasil, período em que a nascente República, ao selecionar os seus mitos e símbolos, consolidou a relevância daquele que tantas vezes se opôs ao Imperador e firmou seu nome nos quadros da historiografia literária brasileira (QUEIROZ, 2011, p. 151), isso com a chancela desses países que assumiam um papel de relevância nos novos rumos políticos e culturais do Brasil.

\section{Referências}

ADAMS, Charles K. (Dir.). Johnson's Universal Cyclopedia. A new edition. Vol I. New York: D. Appleton, 1898.

ALENCAR, José de. Às quintas. In COUTINHO, Afrânio (Org.). A polêmica Alencar-Nabuco. Rio de Janeiro: Tempo Brasileiro, 1965.

Carta a Baptiste Louis Garnier, 11 set. 1863. In: PEREIRA, Patrícia Regina Cavaleiro. "Há muito tempo que não te escrevo...": reunião da correspondência alencariana (edição anotada). Dissertação (Mestrado em Letras). Faculdade de Filosofia, Letras e Ciências Humanas da Universidade de São Paulo, São Paulo, 2012, p. 112.

O teatro brasileiro: a propósito de O Jesuíta. In: O Globo, 26 set. 1875.

Recibo passado ao editor B. L. Garnier. 23 ago. 1870. Seção Manuscritos da Fundação Biblioteca Nacional do Rio de Janeiro. Disponível em:

$<$ http://objdigital.bn.br/acervo digital/div manuscrit os/mss | $0709002 / \mathrm{mss}$ | 070909 002.pdf $\geq$.

Iraçéma: the honey-lips. Tradução de Isabel Burton London: Bickers and son, 1886.

ANDREWS, C.C. Brazil, its condition, its prospects. New York. D. Appleton, 1887.

APPLETON'S Annual Cyclopedia and Register of Important events of the year 1877. New series, vol. II. New York: D. Appleton and Company, 1889.

BLAKE, Augusto V. A. S.. Diccionario bibliographico brazileiro, v. 5. Rio de Janeiro: Imprensa Nacional, 1899.

BOOKSELLERS of today. In: Publishers' Circular and general record of British and foreign literature. London: Sampson Low, v. 531, n. 1. 263, May 1890.

BURTON, Isabel. Letter to José Carlos Rodrigues. 21 May 1872. Fundação Biblioteca Nacional. Acervo de manuscritos. Localização: I-03, 01, 085.

Preface. In BURTON, Richard. The Highlands of the Brazil. London: Tinsley brothers, 1869.

Preface. In: ALENCAR, José de. Iraçéma: the honey-lips. London: Bickers and son, 1886. 
The life of Captain Sir Richard Burton. London: Chapman \& Hall, 1893.

; WILKINS, W. H. The romance of Isabel Lady Burton: the story of her life. London: Huchinson, 1897.

BURTON, Richard F. Highlands of the Brazil. Vol. II. London: Tinsley Brothers, 1869.

Translations. In: The Athenaeum: journal of literature, science, the fine arts, music, and the drama. London: John Francis, no 2313, 24 Feb. 1872, p. 241-243.

CACHIN, Marie-Françoise. Une nation de lecteurs ? La lecture en Angleterre : 1815-1945. Villeurbanne : Presses de l'enssib, 2010.

CORRESPONDENCE. In: The Publishers' and Stationers' Weekly Trade Circular. New York: F. Leypoldt, editor and publisher, n. 20, 14 Nov. 1872 , p. 513.

HARRIS, Philip R. A History of the British Museum Library (1753-1973). London: The British Library, 1998.

Identification of printed books acquired by the British Museum, 1753-1836. In: MANDELBROTE, Giles; TAYLOR, Barry (Org.). Libraries within the library: the origins of the British Library's Printed Collections. London: The British Library, 2009.

HAWES, James W. The Guarany [Preface] (From the Portuguese of José Martiniano de Alencar). In: Overland Monthly and Out West Magazine, San Francisco, v. 21, Second Series, n. 121, Jan. 1893, p. 81.

HEINEBERG, Ilana. Peri com sotaque francês: um estudo preliminar de três traduções de $O$ Guarani no século XIX. In: PELOGGIO, Marcelo; VASCONCELOS, Arlene F.; BEZERRA, Valéria C. (Orgs.) José de Alencar: século XXI. Fortaleza: Edições UFC, 2015, p. 241-265.

KELLOGG, Day Otis (Dir.). New American Supplement to the latest edition of the Encyclopaedia Britannica. Vol. I. New York/Chicago: The Werner Company, 1898.

LEONARD, John W. (Dir.). Men of America: a biographical dictionary of contemporaries. New York: L. R. Hamersly, 1908.

LIVRES NOUVEAUX. In: Le Temps, n. 15134, 20 nov. 1902 , p. 3.
LITERATURE. In: The Glasgow Herald. Glasgow, Scotland. 18 Feb. 1886, p. 3.

LITERATURE: Iracema, the Honey-Lips, a legend of Brazil, by J. de Alencar. In: The Freeman's Journal. Dublin, Ireland, 22 Jan. 1886, p. 2.

LOVELL, Mary S. A rage to live: a biography of Richard and Isabel Burton. New York: First American, 1998.

OGDEN, Rollo. Brazilian Literature. In The Critic, New York: Wyckoff, Seamans \& Benedict, 10 May 1890, p. 234-235.

OVERLAND Reminiscences. In: Overland Monthly and Out West Magazine. San Francisco, v. 1, Second Series, n. 1, Jan-June 1883.

OVERLAND Monthly Announcements for 1893. In: Overland Monthly and Out West Magazine. San Francisco, v. 21, Second Series, n. 126, June 1883, p. 1-8.

QUEIROZ, Juliana M. de. As múltiplas facetas de Joaquim Manoel de Macedo: um estudo de A carteira de meu tio, Memórias do sobrinho de meu tio e A luneta mágica. Tese (Doutorado em Teoria e História Literária). Instituto de Estudos da Linguagem da Universidade Estadual de Campinas. Campinas-SP, 2011.

RAMSEY, M. M. Latin-American Literature. In: WARNER, Charles Dudley (Dir.). Library of the Best Literature. Ancient and Modern. Vol. XXII. New York: J. A. Hill, 18--.

SMITH, Herbert H. Portuguese-Brazilian Literature. In: ADAMS, Charles Kendall. Johnson's Universal Cyclopaedia. A new edition. Vol. VI. New York. D. Appleton and Company, 1899.

THE GUARANY. From the Portuguese of José Martiniano de Alencar. In: Overland Monthly and Out West Magazine. San Francisco, v. 21-22, Second Series, n. 121-132, Jan-Dec. 1893.

WARNER, Charles D. (Dir.). Library of the Best Literature. Ancient and Modern. Vol. XLVI. New York: J. A. Hill \& Company, 18--.

XAVIER, Wiebke R. de A. O encontro do Ubirajara alencariano com a sua primeira tradução alemã de 1886. In PELOGGIO, Marcelo; VASCONCELOS, Arlene F.; BEZERRA, Valéria C. (Orgs.) José de Alencar: século XXI. Fortaleza: Edições UFC, 2015, $\quad$ p. 267-286.

\section{COMO CITAR ESSE ARTIGO}

BEZERRA, Valéria Cristina. The Honey-lips e The Guarany: os romances de José de Alencar em língua inglesa no final do século XIX. Signo, Santa Cruz do Sul, v. 41, n. 72, out. 2016. ISSN 1982-2014. Disponível em: <https://online.unisc.br/seer/index.php/signo/article/view/7140>. Acesso em: doi: http: //dx.doi.org/10.17058/signo.v41i72.7140. 